\title{
AGRESSIVIDADE, VIOLÊNCIA E BUDŌ: TEMAS DA EDUCAÇÃO FÍSICA EM UMA ESCOLA ESTADUAL EM GOIÂNIA
}

\author{
Viviane Lopes Freitas Ueno \\ Secretaria estadual de educação de Goiás, Goiânia, Goiás, Brasil. \\ Marcel Farias de Sousa \\ Faculdade de Educação Física e Dança da Universidade Federal de Goiás, Goiânia, Goiás, Brasil.
}

\begin{abstract}
Resumo
O objetivo deste trabalho é apresentar as percepções de estudantes de uma escola estadual de Goiânia, sobre a relação agressividade e lutas/caminho-via marcial tematizadas nas aulas de educação física. Trata-se de uma pesquisa qualitativa utilizando como instrumentos para a coleta de dados a observação sistemática e participante, avaliações aplicadas no decorrer do bimestre e relato oral. Para a análise do material coletado, estabelecemos os seguintes eixos: compreensão dos alunos sobre as lutas; relação entre gênero e lutas; compreensão sobre a violência e agressividade. Conclui-se que há uma distorção na representação das lutas e uma associação com a temática violência, evidenciando a necessidade do trato pedagógico na escola pela disciplina Educação Física sobre o tema.
\end{abstract}

Palavras-chave: Agressividade. Violência. Luta. Budō. Escola.

\section{Introdução}

A vivência na realidade escolar direciona-nos a uma relação com diversos fenômenos sociais, temáticas diretas ou transversais a essa instituição, como a dimensão da violência, a indisciplina, entre outros. As lutas corporais cada vez mais se afirmam como uma prática esportiva, mas que possui tratos diferenciados nos espaços e campos que são oferecidos: 1) nos $d \overline{o j o} \bar{o}$ (道場) $)^{1}$ ou academias, uma possível consequência desses aspectos é a exacerbação de um "espírito" competitivo; e 2) na escola, local em que essa prática ou é tratada a partir do modelo hegemônico (esportivizado) ou é negligenciada causando uma consequente exclusão desse conteúdo nas aulas de educação física, sendo um dos motivos a relação do conteúdo em questão com a violência, a agressividade e a indevida apropriação desses conceitos e termos. Teixeira (2007) trilha pela compreensão sociológica do universo dos "pitboys", formados por jovens de classe média e alta na cidade do Rio de Janeiro, onde se percebeu que os praticantes de jiu-jitsu brasileiro possuíam um temperamento intempestivo e de grande agressividade. Essa imagem não se torna exclusiva para esse grupo, havendo na sociedade um movimento de generalização que contribui para a criação de um estereótipo equivocado para outros praticantes de lutas.

\footnotetext{
${ }^{1} D \overline{o j} \bar{o}-D \bar{o}$ (道) caminho, $J \bar{o}$ (場) lugar, espaço físico - é o local onde se treinam as artes marciais japonesas. O termo foi emprestado do Zen Budismo, significando "lugar de iluminação", onde os monges praticavam a meditação, a concentração, a respiração, os exercícios físicos e outros mais.
}

Pensar a Prática, Goiânia, v. 17, n. 4, out./dez. 2014 
Dessa forma, a pesquisa desenvolvida, de que resultou este artigo, teve como objetivo compreender e analisar as percepções de alunos do ensino básico de uma escola da rede estadual de Goiás (localizada em Goiânia) sobre a relação agressividade, violência e lutas/caminho-via marcial. O estudo procura trazer a reflexão em torno dos temas da agressividade e lutas/artes marciais, dialogando com a teoria sociológica e psicanalítica. Dialogaremos com as considerações de Erich Fromm sobre o instinto de agressividade e sua formação e na teoria do processo civilizador em Norbert Elias, que aponta para a sublimação e o controle dos instintos como um importante componente para a socialização e o estabelecimento da civilização.

\section{Agressividade e violência: breves considerações}

Quando se fala na relação entre instinto e pulsão, é importante destacarmos que há importantes e diferentes traduções da palavra alemã Trieb, usada por Freud como um dos conceitos básicos da sua teoria. Em inglês essa palavra foi traduzida como instinkt, que na língua portuguesa se traduziu como instinto. Em Freud, a palavra alemã Instinkt era usada para designar "[...] um comportamento animal fixado por hereditariedade, característico da espécie, pré-formado no seu desenvolvimento" (LAPLANCHE; PONTALIS, 1991, p. 394). Pulsão seria então um processo dinâmico que consiste numa pressão ou força que faz o organismo tender para um objetivo, situada na fronteira entre o psíquico e o somático (FREUD, 1996).

Já a agressividade é considerada como uma manifestação não racionalista dessa força, um ato natural no indivíduo quando sua sobrevivência está ameaçada. Assim, é praticada como defesa para conservar a vida ou integridade do ser, bem como para saciar suas necessidades vitais. Por isso, Freud afirma não existir instinto violento e sim um impulso agressivo, presente tanto nos homens como nos animais. No ser humano, a pulsão agressiva coloca-se em oposição aos objetivos da civilização e ocasiona conflito entre as pessoas (FREUD, 1996). O Superego seria a instância que conformaria o homem a se submeter à lei social por esta ter-se tornado uma lei internalizada por meio dos mecanismos de identificação.

Para Freud, o homem é regido por dois tipos de pulsão: a pulsão de vida, que é representada pela sexualidade e é responsável pelas ligações, pelo desenvolvimento e pelo crescimento; e a pulsão de morte, podendo efetuar, de forma silenciosa, um trabalho destrutivo, e que tem sua origem numa necessidade de aliviar as tensões, a pressão que a natureza provoca nos seres. Nesse sentido, os atos de violência cometidos contra o outro são, na perspectiva freudiana, a expressão mais pura da pulsão de morte. A agressividade é resultado da mistura das pulsões de vida ou sexuais com as pulsões de morte, uma vez que ela necessita de uma ligação com o outro, e indica uma tentativa de expulsão das pulsões de morte, que, se ficassem somente voltadas para o eu, poderiam realmente levar à autodestruição, conforme expõe Freud (apud PRATA, 2000).

Erich Fromm, ao considerar que o ser humano possui momentos de destrutividade ou construtividade, pende a aceitar a possibilidade de uma sociedade mais consciente e harmoniosa, que inevitavelmente levaria à substituição de um caráter social patológico por outros valores mais construtivos, que colaborariam para uma sociedade mais justa (FROMM, 1987). Não negará a importância instintual e pulsional dos desejos sexuais, 
entretanto fornecerá uma visão mais humanista e social a essas pulsões, defendendo não existir qualidades boas ou más inatas no ser humano. Propõe também a existência de uma agressividade instintual na natureza, que se torna condição essencial para sua própria sobrevivência.

Quanto à violência, entende-se como várias formas de comportamento, ativo ou passivo, motor ou verbal, que visam prejudicar direta ou indiretamente alguém. Conforme Pereira (1975), a violência tem conotação tanto física quanto primordial. Assim, a violência é uma expressão essencialmente humana, de caráter histórico, que lhe concede a condição de ser universal e específica nas variadas formas de organização social, uma vez que sempre esteve presente nas diferentes sociedades, com a sua concretização em eventos específicos inerentemente ligados ao modo como os homens se organizam em sociedade.

Dessa forma, violência e agressividade não devem ser confundidas, principalmente no âmbito das relações sociais, pois se pode incorrer no erro de se considerar a violência como um fato espontâneo e presumível do ser humano, isto é, um comportamento natural. $\mathrm{O}$ que se pode concluir é entendermos a agressividade como forma de o ser humano se auto preservar, defender-se e buscar a satisfação de suas necessidades, enquanto a violência advém de uma desorganização patológica dessa instância.

No entanto, não se pode simplesmente afirmar que a violência seja algo apenas patológico, uma vez que a busca pela satisfação pessoal faz com que a moralidade seja dissolvida e princípios ético-morais sejam negligenciados. Assim, podemos atribuir a diversos fatores de ordem econômica, social, cultural e psicológica o advento e aumento da violência.

\section{Violência, lutas e budō}

As formas de autodefesa são, provavelmente, tão antigas quanto a humanidade. De acordo com Barreira (2002), são tidas como práticas corporais e culturais, carregadas de significados construídos historicamente, e que estabelecem relações constantes com as sociedades onde se inserem, buscando um equilíbrio essencial para o desenvolvimento integral do indivíduo.

Algumas manifestações de lutas/artes-vias marciais passaram pelo processo de esportivização na modernidade. Para Bracht (1997), Elias e Dunning (1992), o esporte passa a ter a função de atenuar, ou mesmo de desviar as tensões sociais. A agressividade ativa de origem social é transferida para ações esportivas, não acometendo as verdadeiras causas, e sim direcionadas ao agir agressivo nas competições esportivas.

Essas práticas são, inevitavelmente, correlacionadas à violência. Isso não quer dizer que não haja outros motivos que influenciem na desfiguração das lutas, que inicialmente estavam relacionadas com o desenvolvimento de técnicas de autoproteção e combates, tornando-se posteriormente uma forma de ascensão espiritual. Assim, o processo de esportivização das lutas/artes-vias marciais ocorre de acordo com as transformações da modernidade, com o avanço do capitalismo e a apropriação dessas práticas corporais pela indústria cultural.

As lutas (esportivizadas) apresentam parcialmente algumas de suas características fundamentais, como o desenvolvimento de técnicas de combate para sobrepujar o adver- 
sário. No entanto, esse processo também ressignifica algumas lutas japonesas ${ }^{2}$, uma vez que sua essência é pautada numa compreensão mais ampla sobre a formação de um sujeito, pensamento este advindo e influenciado pela religiosidade e espiritualidade presente na própria nação japonesa.

\section{A pesquisa}

Para o desenvolvimento deste estudo foi realizada uma pesquisa participante, o que tornou necessária a adoção de uma abordagem qualitativa para permitir a compreensão mais profunda dos campos sociais e dos sentidos neles presentes, na medida em que remetem a uma teia de significados.

Participaram desta pesquisa estudantes (360 no total) do 1ำ e 2o ano do ensino médio, da rede estadual de ensino no município de Goiânia (GO). A seleção do colégio foi de forma intencional, por afinidade profissional. Para tanto foi estabelecido um plano de ensino com um conjunto de 35 aulas, para todo o semestre de 2011. A escola não possuía estrutura adequada para a prática, mas oferecia um tatame de EVA montado no pátio entre as salas de aulas. Além do tatame foram utilizados vídeos e texto preparados especificamente para a abordagem do tema. A abordagem desse conteúdo surgiu a partir de diálogos com os estudantes, onde se evidenciou a curiosidade e o interesse destes nas práticas de lutas. Percebemos, então, a necessidade de abordar tal conteúdo juntamente com o tema da violência, fenômeno bastante presente na região em que a escola se encontra.

As aulas propostas pretendiam oferecer subsídios para que todos os estudantes conhecessem os diversos aspectos relacionados à prática de lutas, como, por exemplo, as suas origens e significados em nossa e em outras culturas, as diversas formas de praticálas, suas técnicas, suas regras. Além disso, esse tema propicia um rico momento para o desenvolvimento de valores e atitudes.

O objetivo da aplicação era compreender a luta como uma prática milenar que traz elementos importantes de algumas culturas (em especial, do mundo oriental). Procuramos proporcionar uma análise reflexiva e crítica mediante as vivências de elementos técnicotáticos básicos das práticas de algumas lutas, tais como o karate e o jiu-jitsu brasileiro. Essas práticas foram abordadas nas dimensões históricas, sociais, culturais e filosóficas, que são intrínsecas a essas atividades.

Os procedimentos de coleta de dados foram realizados por meio da observação sistemática, com adoção do diário de campo e análise documental mediante a utilização de instrumentos de avaliação da disciplina (apresentações de trabalhos, avaliações orais e escritas).

Ao iniciarmos o estudo, surgiram muitos imprevistos, como paralisações, emenda de feriados que não estavam previstos no calendário e falta de professores na unidade, o que levou a um grande número de aulas ministradas em duas ou três turmas ao mesmo tempo. As limitações físicas também dificultaram o trabalho: com as aulas no pátio, a dis-

\footnotetext{
${ }^{2}$ A palavra japonesa budō é composta por dois caracteres: $b u$ (武) e o caractere $d \bar{o}$ (道), que significa caminho ou disciplina (LOUIS, 2008). Assim, temos a palavra budō (武道), o caminho do guerreiro e da atividade iluminada. O budō não é um conceito fechado, pois possui considerações e conceituações vindas de várias fontes. No entanto, essas conceituações compreendem uma série de valores morais que apontam as práticas marciais como um valioso elemento cultural japonês.
}

Pensar a Prática, Goiânia, v. 17, n. 4, out./dez. 2014 
persão dos alunos era maior, o barulho gerado nas aulas incomodava alguns professores que tinham uma visão de educação física como forma de recreação, entre outras dificuldades. Essa falta de estrutura também se encontrava presente no setor administrativo e de apoio pedagógico, tendo como consequência a inviabilização de alguns materiais didáticos.

Para a análise do material coletado, foram estabelecidos os seguintes eixos: Compreensão dos alunos sobre as lutas, Relação gênero e lutas, Compreensão sobre a violência e agressividade.

\section{a) Compreensão dos estudantes sobre as lutas/artes marciais}

Para identificarmos o que os estudantes compreendiam sobre as lutas, logo na primeira aula foi feita uma atividade diagnóstica avaliativa escrita com a seguinte pergunta: "Para você, o que é luta?". Assim, temos o seguinte apontamento:

Não houve respostas que trouxessem uma noção mais ampla sobre a concepção de luta, geralmente associada ao plano individual; não há um reconhecimento imediato de que as formas de lutas também se dão no campo coletivo e social. Ao compreendermos as lutas como um tipo de ação social, conforme aponta Sousa (2010) a partir do modelo teórico sociológico proposto por Max Weber, pode-se então afirmar que elas ocorrem em diversas instâncias, no plano concreto ou mesmo no subjetivo. Outro ponto a se considerar é que surgiu uma porcentagem curiosa de respostas em que se tem a imediata associação das práticas marciais com a mídia.

Em uma segunda avaliação diagnóstica oral com os estudantes o que mais chama a atenção é a relação estabelecida entre luta e violência, algo que também se evidenciou nas avaliações escritas.

Luta é tipo assim, violência, dar porrada, bater forte, onde o mais forte sai ganhando

[...] (Avaliação escrita, depoimento 1, J., 1ํo ano matutino, 2011).

Essa concepção das lutas, presente nas falas dos estudantes, pode ocorrer em resposta às transformações que elas estão sofrendo, firmando-se cada vez mais como práticas esportivas, por meio de uma espetacularização e comercialização das lutas, que para muitos se tornou sinônimo de violência.

Luta é um esporte violento e sem sentido (Avaliação escrita, depoimento 7, D., 1을 ano matutino, 2011).

Eu entendo que a luta é um esporte violento onde se machuca para ganhar. [...] não vejo a luta como um esporte normal, mas como um esporte onde se bate (Avaliação escrita, depoimento 8, J. K., $1^{\circ}$ ano matutino, 2011).

Alguns praticantes de lutas utilizam esse conhecimento de maneira inadequada, e assim contribuem também para que a relação entre lutas e violência seja difundida socialmente. É o que aponta Teixeira (2007), ao abordar o caso de lutadores do Rio de Janeiro 
que passaram a ser chamados de "pit boys", numa analogia com os cachorros da raça pit bull. Desse modo, é comum a ideia de que o aumento de um certo tipo de violência urbana é decorrente da grande difusão de lutas entre os jovens.

A influência da mídia também é algo muito marcante quando justificam suas respostas baseando-se em filmes e jogos, ao reforçarem a ideia de lutas apenas como prática esportiva. Foi possível perceber isso na 1a avaliação escrita, uma vez que $8 \%$ dos alunos, ao serem questionados quanto ao seu entendimento sobre luta, fizeram uma correlação entre essa prática e a mídia.

Acredito que conhecemos as lutas marciais só por causa dos filmes americanos que relatam o Kung-fu, o Karate etc. (Avaliação oral, depoimento 3, C., $1^{\circ}$ ano matutino, 2011).

Quando falamos em luta, penso em filmes de ação e brigas (Avaliação oral, depoimento 9, J., 1ㅇano matutino, 2011).

E a partir da intervenção pedagógica, alguns estudantes demonstraram que a experiência foi positiva por ampliar o seu conhecimento sobre as modalidades e tipos de lutas:

Nossa, achei fantástico descobrir outras formas de lutas, para mim só existia o Karate, as outras eu pensava que eram fantasiosas, que só existia em desenhos e filmes (Avaliação oral, depoimento 2, T., 1 o ano matutino, 2011).

Pimenta (2007) aponta que os veículos de comunicação muitas vezes tratam as lutas de forma simplista, marginalizando processos históricos e sociais que contribuíram para sua formação. Desse modo, percebemos que a visível mercantilização dos diferentes setores sociais (incluindo o meio esportivo) nas últimas décadas expõe e valoriza a dimensão extrema e agressiva da prática de lutas esportivizadas.

Por outro lado, o formato da imitação faz-se bastante presente no caráter educacional e mesmo cultural de atletas de esportes em geral, refletindo na representação de valores, símbolos e ídolos de sua educação e cultura. Um exemplo desse pensamento é a reprodução da conduta agressiva de jovens desportistas (ou mesmo do cidadão), fãs de atletas reconhecidamente violentos pela sociedade (BENTO apud MOCARZEL, 2011). A ação pedagógica proposta procurou apresentar os conceitos relacionados ao tema e os estilos de lutas, por meio de textos, aulas expositivas e práticas. Iniciou-se uma discussão com os estudantes para que eles expusessem as lutas sobre as quais tinham algum tipo de conhecimento, no qual foram apontadas as práticas mais populares, como: karate, jud, boxe, kung-fu, jiu-jitsu, entre outras. Algumas modalidades de lutas os estudantes não sabiam nomear, mas deram algumas características para que pudéssemos identificá-las conjuntamente. Assim, foi possível perceber que a maioria deles nunca teve uma experiência com as lutas, com base nas seguintes argumentações: medo; devido à forma como as lutas são apresentadas pelos meios de comunicação de massa; por falta de acesso aos espaços de práticas; e por dificuldades financeiras. Quanto aos que tiveram contato, apresentaram um conhecimento pautado apenas na dimensão (unidimensional) técnica. Pôde-se 
verificar isso na fala de uma aluna praticante de karate ao ser indagada acerca do que ela sabe sobre a arte marcial que pratica:

Não conheço a história do karate, sei que veio do Japão, [...] ah, se eu souber socar e chutar vou ganhar os campeonatos, isso que importa! (Avaliação oral, depoimento 4, M., 2o ano matutino, 2011).

Se, num primeiro momento, os alunos foram questionados quanto à compreensão sobre as lutas/artes-vias marciais, posteriormente, após o desenvolvimento teórico-metodológico do ensino das lutas, os alunos realizaram uma atividade avaliativa descritiva, respondendo à mesma pergunta inicial, agora apontando: "O que mudou, acrescentou, após as explicações e as aulas práticas no decorrer do semestre? Se mudou, o que mudou? Se não mudou, por quê?".

[...] antes eu imaginava, dentro de uma luta, grosseria, espancamento e etc. E hoje, estudando e praticando sobre o assunto, vejo que não tem nada a ver com o que eu imaginava, porque contém dentro da luta respeito um ao outro, também tem parceria, amizade e regras (Avaliação escrita, depoimento 5, J. P., 2ㅇano matutino, 2011).

$\mathrm{Na}$ análise das respostas, foi satisfatório perceber que a maioria dos estudantes conseguiu distanciar a relação entre lutas e violência, entendendo que essas atividades são praticadas e guiadas por princípios religiosos e filosóficos. E que por meio das lutas podemos abordar valores sociais, o que corrobora com Battigne (apud SOUSA, 2011) ao referir que as lutas têm o intuito de desenvolver qualidades no indivíduo, tais como a coragem, o autoconhecimento, a autoconfiança e o autocontrole, estimulando um respeito integrativo pelas regras, assim como a cordialidade interpessoal.

Ao defrontarmos as falas iniciais dos alunos com as posteriores às aulas, percebemos que existe uma distorção das lutas no imaginário social, talvez pelo processo de esportivização, pela forma que a mídia expõe essa prática ou pelo simples fato de não existir nas escolas aulas que contemplem esse tema. Assim, fica patente a necessidade de fomentar, a partir de vivências e leituras críticas sobre as lutas, inicialmente estimuladas na escola, que poderão ser posteriormente recuperadas e reformuladas pelos alunos no seu cotidiano de vida, no caso de passarem num momento ou outro a ter contato com alguma atividade de luta, como praticante ou expectador.

\section{b) Relação gênero e lutas}

O sexismo é um ponto muito relevante ao abordarmos o tema lutas na escola, estando enraizada a ideia de lutas como uma prática estritamente masculina. As práticas corporais competitivas, com contato físico, são vistas como uma forma de "tornar um menino em homem", aumentando a sua virilidade, masculinidade, capacidade de desprezar a dor, controle do corpo e vontade de ganhar (FERRETI; KNIJNIK, 2007). 
Embora o estudo não tivesse inicialmente como objetivo uma abordagem sobre essa dimensão, fez-se necessário discutirmos esse tema, uma vez que durante as aulas surgiram muitas situações relacionadas a tal assunto, o que inicialmente gerou certo desconforto em alguns estudantes.

Durante as aulas práticas apenas alguns estudantes hesitaram em participar. Ao questionar uma aluna que se negou a realizar a atividade proposta, a briga de galo, ela alegou:

Eu acho que só homem faz, porque eles são mais fortes [...], pra mim não é esporte de mulher (Depoimento 14, X., diário de campo, 2011).

O depoimento anterior revela não somente uma posição, mas também evidencia que a noção de agressividade está associada à masculinidade. Para Da Silva (2000) o comportamento agressivo é idêntico em homens e mulheres, ou seja, os circuitos neurais responsáveis pela reação de raiva são os mesmos. Contudo, há diferenças entre os sexos, relacionadas às situações em que tal comportamento é manifestado, e os mecanismos hormonais que desencadeiam ou inibem a agressividade. $\mathrm{O}$ fator social também tem grande influência sobre esse comportamento, devido à constituição de uma sociedade heteronormativa fundada em uma estrutura patriarcalista, em que o homem recebe uma educação que valoriza comportamentos agressivos, ao passo que com a mulher ocorre o oposto. Podemos observar isso nas primeiras edições dos Jogos Olímpicos, bem como nos jogos gregos da antiguidade, os quais não admitiam mulheres ${ }^{3}$.

Após a leitura de alguns textos, os estudantes começaram a superar alguns preconceitos presentes nas aulas, como o fato de ter que tocar ou até mesmo ficar muito próximo do colega, e principalmente quando do sexo oposto; boa parte achava muito invasivas algumas posições, como, por exemplo, a montada. O simples fato de tirar o calçado para pisar no tatame gerava grande tumulto no início das práticas. Entendemos esse comportamento, pois na nossa sociedade não é comum ficarmos descalços em ambientes públicos. Após explicação sobre o motivo para se tirar o calçado, como algo extremamente significativo na sociedade japonesa, os alunos ficaram mais à vontade, havendo assim uma participação efetiva.

Meu conceito mudou muito depois de ler os textos. Pois pensava que era apenas uma luta sem regras, mas é completamente diferente, há muitas regras e acima de tudo muito respeito com o tatame (Avaliação escrita, depoimento 13, P., 2 o ano matutino, 2011).

Os preconceitos, estereótipos e discriminações relacionados com a mulher atleta ou praticante de lutas tem precedentes desde a época da Grécia Antiga, com repercussão na maior parte das culturas ocidentais (AZEVEDO apud SILVA, 1994). A participação da mulher no que diz respeito às lutas no Brasil é ainda pouco aceita e alguns fatos contribuíram para essa situação, como o Decreto-Lei no 3.199/1941, que propunha: “[...]

\footnotetext{
${ }^{3} \mathrm{Na}$ Grécia Antiga, a participação das mulheres era proibida. Assim como os escravos, as mulheres não eram consideradas cidadãs, e acreditava-se principalmente que a atividade física vigorosa poderia deteriorar sua saúde e afetar sua capacidade de ter filhos, e, sendo assim, as práticas esportivas eram tradicionalmente de domínio masculino (CHIÉS, 2006).
}

Pensar a Prática, Goiânia, v. 17, n. 4, out./dez. 2014 
não é permitida a prática de lutas de qualquer natureza" às mulheres. Como outro exemplo, temos que, na época da ditadura vigente entre 1964 e 1985, um militar tentou proibir a prática das artes marciais sem nenhuma consulta às mulheres ou aos especialistas em medicina desportiva (SOARES apud SILVA, 1994). Esses fatos deixaram grandes marcas no que diz respeito à prática de lutas pelas mulheres, estando estigmatizada como algo "proibido", ou mesmo impróprio para mulheres. Tal afirmação pode ser contextualizada ao rememorar algumas falas:

Eu pensava que somente os homens lutavam, mas percebi que as mulheres também lutam (Depoimento 6, Y., diário de campo, 2011).

\section{c) Compreensão de violência e agressividade}

Por meio de algumas aulas práticas foram desenvolvidas técnicas de soco, chute e de luta de solo, provindos do karate e do jiu-jitsu, o que gerou uma ansiedade para que se efetivassem os momentos de oposição, a luta. Ocasionou, assim, algumas atitudes excessivas, como socos muito fortes e a nítida intenção de "machucar" o colega.

Alguns garotos que eram participativos e interessados nas aulas teóricas não queriam participar das aulas práticas justificando que,

[...] poderiam ser humilhados caso não conseguissem realizar algum movimento, isso seria vexatório diante dos colegas, uma vez que para eles as atividades tinham como objetivo apenas a sobrepujança (Depoimento 15, W., diário de campo, 2011).

O pouco conhecimento sobre as lutas/artes marciais contribui para a formação de uma visão preconceituosa dessas práticas. Segundo Araújo (2005), as pessoas acreditam que a prática das lutas estimula a violência e que o praticante destas é, assim, uma pessoa violenta.

Após conceituar o termo luta e vivenciar técnicas de combate, a partir de um estudo feito por textos sobre a temática da violência, os estudantes perceberam que essa dimensão não era necessariamente um pré-requisito para a participação nas aulas práticas. Assim, houve um aumento nas participações nas aulas. Percebemos também que em um primeiro momento os estudantes queriam usar somente a força. Posteriormente a "postura" do grupo no tatame estava bem diferente,

Eu entendi que a luta não é espancar uns aos outros, que não precisa de violência [...] (Avaliação escrita, depoimento 11, 2ํㅡㅁ ano matutino, 2011).

Bandeira (2006) observa que a cultura e a educação nos países berços das artes marciais, como o Japão, a Coréia e a China, tem grande influência do budismo, doutrina filosófica alicerçada na espiritualidade, meditação e concentração. Gadotti (2002) diz que o pensamento pedagógico oriental mostra aspectos espiritualistas e não agressivos da 
educação nesses países. Valores que são ligados, sobretudo, à religião, dentre as quais se destacam o taoísmo, o budismo e o hinduísmo. Essas doutrinas compõem a base filosófica das artes marciais nascidas em toda a Ásia.

Ao questionarmos os estudantes sobre o que entendiam por violência, a maioria das respostas relacionava o termo ao contato físico, que em um primeiro momento se traduzia em lutas.

Eu acho que violência é sair dando porrada por aí, ou melhor tomando (Avaliação oral, depoimento 10, N., 2º ano matutino, 2011).

Quando falo em luta para mim é um tipo de violência com socos, murros contra seu adversário (Avaliação oral, depoimento 12, U., 2ำ ano matutino, 2011).

Para contemplarmos essa temática, foi feita uma abordagem sobre a distinção entre os termos violência e agressividade, trazendo também, através de textos e imagens, esclarecimentos sobre a violência simbólica. Segundo Elias e Dunning (1992), esse tipo de violência não é física, mas é de comportamento, podendo ser verbal, pelas ações das pessoas, ou, ainda, pela discriminação racial, sexual ou religiosa que existe na sociedade. Trata-se de ações abstratas de superioridade de uma pessoa ou grupo sobre o outro, ou seja, “[...] a violência é real ou simbólica, isto é, se apresenta na forma de uma agressão física direta ou envolve simplesmente atitudes verbais e/ou atitudes não verbais" (ELIAS; DUNNING, 1992, p. 330).

Ao deixar claro que violência é algo que vai muito além do aspecto físico, como é o caso da violência simbólica, houve muita confusão entre os estudantes e certo desconforto. À medida que aprofundávamos na discussão, os olhares dos alunos voltaram-se para as paredes da sala de aula, que estavam todas pichadas, as janelas quebradas. Enfim, perceberam que estavam expostos a uma situação de violência naquele momento.

\section{Considerações finais: lutas/artes-caminhos marciais na escola}

Algumas lutas/artes marciais tradicionalmente são acompanhadas de uma filosofia, em geral pautada por princípios de não agressão e respeito ao próximo, sendo esses princípios e a religiosidade presentes nessas práticas como elementos constituintes de um ideal de moralidade e de uma conduta autocontrolada. No entanto, ao analisarmos as percepções dos alunos sobre a relação agressividade e lutas, verificamos uma distorção nos conceitos que permeiam essas práticas.

Mesmo diante de toda dificuldade encontrada no decorrer da pesquisa, como um espaço físico limitado, paralisações, frequentes "subidas" de aula, feriados não calendarizados e a falta de conhecimento sobre as lutas/artes marciais por parte dos estudantes e do próprio grupo docente (que levava a uma resistência do conteúdo na Educação Física escolar), foi possível compreendermos a concepção dos alunos quanto às lutas/artes marciais.

Numa compreensão geral da pesquisa evidencia-se que o conteúdo, para muitos, é uma grande novidade; deparamo-nos com relatos de estudantes que entendiam as lutas como práticas existentes somente em filmes, ou desenhos. Percebemos também a influência da mídia e do processo de esportivização das lutas nas falas dos estudantes, quando 
justificam suas respostas quanto ao que entendem por artes marciais, com base em filmes e jogos.

No decorrer das aulas propostas, os estudantes começaram a distanciar as lutas/artes marciais da violência, porém, ao mesmo tempo, excluíam questões sobre agressividade, mostrando que ainda tinham a ideia de que violência e agressividade eram sinônimos. Fez-se necessário, então, um trato específico dessa temática, em que os estudantes demonstraram, por meio de gestos e feições, surpresa ao diferenciar esses dois termos e entender alguns aspectos ou tipos de violência, como, por exemplo, a simbólica, muito citada nas aulas.

Dessa forma, foi percebido que, a partir de uma abordagem teórico-prática, os estudantes começaram a ampliar sua compreensão acerca das lutas/artes marciais. O interesse e a curiosidade foram pontos que favoreceram esse resultado, evidenciando a carência e necessidade de um trato pedagógico pela disciplina curricular de Educação Física na escola sobre o tema lutas.

\title{
FAGGRESSION, VIOLENCE AND BUDŌ: ISSUES OF PHYSICAL EDUCATION A STATE SCHOOL IN GOIÂNIA
}

\begin{abstract}
The objective of this paper is to present the perceptions of students at a state school in Goiania, about the relationship aggressiveness and fighting/pathway martial thematized of physical education classes. This is a qualitative study using as instruments for data collection systematic observation participant evaluations applied during the quarter and oral report. For data analysis established the following priorities: student understanding of fights; relationship between gender and fights; understanding of violence and aggressiveness. We concluded that there is a distortion in the representation of the fights and an association with violence theme, highlighting the need for pedagogical approach in school for Physical Education on the subject.
\end{abstract}

Keywords: Aggressiveness. Violence. Fight. Budō. School.

AGRESIÓN, VIOLENCIA Y BUDŌ: TEMAS DE LA EDUCACIÓN FÍSICA EN UNA ESCUELA ESTATAL EN GOIANIA

\footnotetext{
Resumen

El objetivo de este trabajo es presentar las percepciones de los estudiantes en una escuela estatal en Goiania, en relación a la agresión y lucha/camino-vía marcial en clases de educación física. Se trata de una investigación cualitativa, utilizando como instrumentos para la recopilación de datos la observación sistemática y participante, evaluaciones aplicadas durante el trimestre y relato oral. Para el análisis de los datos establecido los siguientes ejes: comprensión de los alumnos sobre luchas; relación entre género y luchas; comprensión sobre la violencia y agresión. Se concluye que existe una distorsión en la representación de las luchas y una asociación con el tema violencia, evidenciando la necesidad del trato pedagógico en la escuela por la disciplina Educación Física.

Palabras clave: Agresión. Violencia. Lucha. Budō. Escuela.
} 


\section{Referências}

ARAÚJO, E. D. Agressividade x violência. Fighter Magazine, São Paulo, n. 5, p. 23, 2005.

BANDEIRA, H. R. Percepções de alunos de karatê sobre agressividade/violência: aplicações educacionais no ensino das artes marciais. 2006. Dissertação (Mestrado em Educação) - Pontifícia Universidade Católica do Rio Grande do Sul, Porto Alegre, 2006. Disponível em: <http://www.bdae.org.br/dspace/handle/123456789/696>. Acesso em: 12 set. 2013.

BARREIRA, C. R. A.; MASSIMI, M. A moralidade e a atitude mental no karate-do no pensamento de Gichin Funakoshi. Memorandum, Belo Horizonte: UFMG; Ribeirão Preto: USP, v. 2, p. 39-54, abr. 2002. Disponível em: $<$ http://www.fafich.ufmg.br/ memorandum/artigos02/barreira01.htm>. Acesso: 20 maio 2011.

BETTELHEIM, B. Freud e alma humana. 12. ed. São Paulo: Cultrix, 1998.

BRACHT, V. Sociologia crítica do esporte: uma introdução. Vitória, ES: UFES, 1997.

CHIÉS, P. V. "Eis quem surge no estádio: é Atalante!" A história das mulheres nos Jogos Gregos. Movimento, Porto Alegre, v. 12, n. 3, p. 99-121, 2006. Disponível em: $<$ http://seer.ufrgs.br/Movimento/article/view/2911>. Acesso em: 16 jul. 2011.

DA SILVA, E. G. Manifestação de comportamentos agressivos em praticantes de artes marciais. EFDeportes - Revista digital, Buenos Aires, año 5, n. 25, set. 2000. Disponível em: <http://www.efdeportes.com/efd25/artesm.htm>. Acesso em: 21 maio 2001.

ELIAS, N.; DUNNING, E. A busca da excitação. Lisboa: Difel, 1992.

FERRETTI, C.; KNIJNIK, D. Mulheres podem praticar lutas? Um estudo sobre as representações sociais de lutadoras universitárias. Movimento, Porto Alegre, v. 13, n. 1, p. 5780, 2007. Disponível em: <http://seer.ufrgs.br/Movimento/article/view/2925/1559>. Acesso: 16 jul. 2011.

FREUD, S. O Ego e o Id. In: FREUD, S. Obras psicológicas de Sigmund Freud: edição standard brasileira volume XVII. Comentários e notas de James Strachey; em colaboração com Anna Freud; traduzido do alemão e inglês sob a direção geral de Jayme Salomão. Rio de Janeiro, RJ: Imago, 1996.

FROMM, E. Anatomia da destrutividade humana. Tradução de Marco Aurélio Souza Matos. 2. ed. Rio de Janeiro: Guanabara, 1987.

GADOTTI, M. História das ideias pedagógicas. São Paulo: Ática, 2002. 
LAPLANCHE, J.; PONTALIS, J. B. Vocabulários da psicanálise. 11. ed. São Paulo: Martins Fontes, 1991.

LOUIS, F. O Japão: dicionário e civilização. Tradução Álvaro David Hwang; revisão técnica Jorge Junior do Prado e Jusara Kazue Ichioka. São Paulo: Globo, 2008.

MOCARZEL, R. S. Artes marciais e jovens: violência ou valores educacionais? Um estudo de caso de um estilo de Kung-Fu. 2011. 108 p. Dissertação (Mestrado em Ciências da Atividade Física) - Universidade Salgado de Oliveira, Niterói, 2011. Disponível em: $<$ http://www.kungfurj.com.br/wp-content/uploads/2011/02/DISSERTAÇÃOCOMPLETA.pdf $>$. Acesso em: 15 maio 2011.

PEREIRA, J. Violência: uma análise do "Homo Brutalis". São Paulo: Alfa-Ômega, 1975. (Coleção Atualidade, 1).

PIMENTA, T. F. A constituição de um sub campo do esporte: o caso do Taekwondo. 2007. 229 p. Dissertação (Mestrado) - Universidade Federal do Paraná, Curitiba, 2007. Disponível em: $\quad<$ http://www.pgsocio.ufpr.br/docs/defesa/dissertacoes/2007/thiagopimenta.pdf $>$. Acesso em: 12 set. 2013.

PRATA, R. M. Violência, educação e subjetividade: algumas reflexões sobre a violência em jovens na atualidade. In: CONFERÊNCIA DE PESQUISA SÓCIO-CULTURAL, 3., 2000. Anais..., Campinas, SP, 2000. Disponível em: <www.fae.unicamp.br/br2000/indit.htm>. Acesso em: 15 maio 2011.

SILVA, G. P. Histórico da mulher no Judô: preconceitos, estereótipos e discriminações. Motrivivência, Florianópolis, v. 5, n. 5, p. 195-207, jan. 1994. Disponível em: $<$ https://periodicos.ufsc.br/index.php/motrivivencia/article/view/14666/13447>. Acesso em: 12 set. 2013.

SOUSA, M. Do conceito de bun bu ryo do à atividade esportiva: a racionalidade moderna nas lutas marciais tradicionais. Dissertação (Mestrado em Sociologia) - Universidade Federal de Goiânia, Goiânia, 2010. Disponível em: $<$ http://www.dominiopublico.gov.br/pesquisa/DetalheObraForm.do? select_action $=\&$ co_obra $=203578>$. Acesso em: 15 maio 2011.

SOUSA, O. et al. Estudo comparativo de agressividade entre praticantes e não praticantes de desportos de combate - Karate. In: SIMPÓSIO DE INVESTIGAÇÃO EM PSICOLOGIA, 7., 2010. Actas..., Portugal: Universidade do Minho, 2010. Disponível em: $<$ http://www.fnkp.pt/uploads/writer_file/document/249/Estudo_Comparativo_de_Agressi vidade_entre_Praticantes_e_N_o_Praticantes_de_Desportos_de_Combate_Karate.pdf>. Acesso em: 29 dez. 2014.

TEIXEIRA, A. C. Esporte e violência no Jiu-Jitsu: o caso dos "pit-boys". 2007. 160 f. Dissertação (Mestrado) - Curso de Ciências Sociais, Pontifícia Universidade Católica do 
Rio de Janeiro, Rio de Janeiro, 2007. Disponível em: $<$ http://www.maxwell.lambda.ele.puc-rio.br/Busca_etds.php? strSecao=resultado\&nrSeq=11860@2>. Acesso em: 12 set. 2013.

Recebido em: 22/04/2014

Revisado em: 26/06/2014

Aprovado em: 27/11/2014

Endereço para correspondência:

zenoliavix@gmail.comcevijp@yahoo.com.br

Lopes Freitas Ueno

UFG - Universidade Federal de Goiás

CNPJ: 01567601/0001-43

Campus Samambaia -Prédio da Reitoria.

CEP 74690-900

Goiânia - Goiás - Brasil. 